\title{
Images and reflections: photography in the pursuit of public health
}

\author{
Nigel Bruce
}

The photographic image has long been used in journalism to document events and circumstances, to attract attention, and to stimulate debate and action. That of itself implies that photography can contribute to change in the social and political climate, which in turn can have a powerful influence on public health. Whether or not photography is also an "art" form, with all the subtlety of expression and interpretation associated with that label, has been a more contentious issue. Whatever the real reasons for London's Victoria and Albert Museum opening the Canon Photographic Gallery in 1998, this development on the part of the Art establishment has been seen as rendering "meaningless any further debate on the validity of photography as art". ${ }^{1}$ (Figure 1 ).

Consideration of whether or not photography is art is relevant to this discussion because of the growing recognition of the value of art in public health and health promotion. Art is seen as an important and effective means of involving people in activities that promote health, and in mediating between everyday life experience and scientifically based knowledge of what affects health-so that people are "touched rather than indoctrinated" by health messages. ${ }^{2}$ Whatever direction the debate about photography and art takes, experience has shown that photography has a valuable part to play in community health and development. Furthermore, its use is not restricted to people

Department of Public Health, University of Liverpool, Whelan Building, Quadrangle, Liverpool L69 3 GB

Correspondence to: Dr Bruce (ngb@liv.ac.uk)

Accepted for publication 30 January 2000

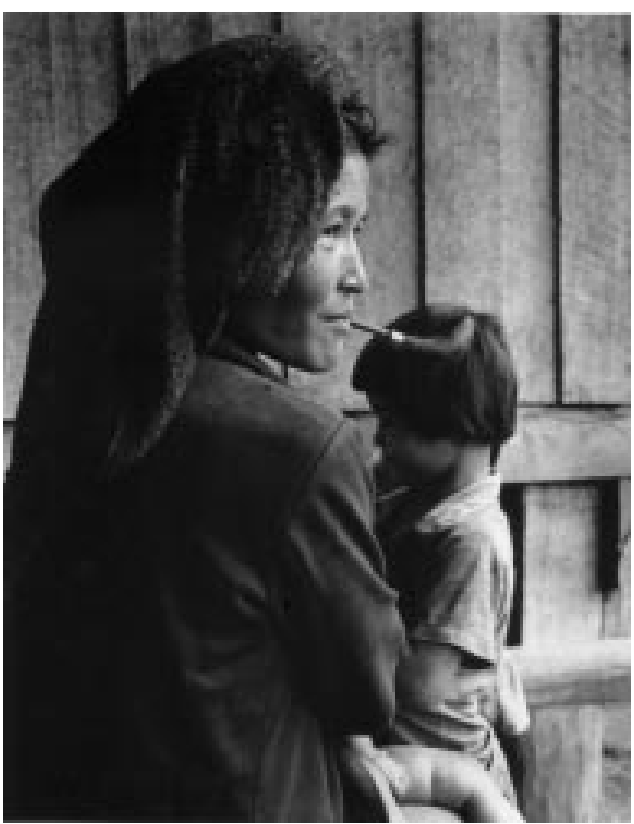

Figure 1 The home environment is a complex yet important influence on the health and development of the young child. Tribal home, northern Thailand. with professional knowledge and skills. Individuals and groups are able to use the medium to express their health related needs and views, and there are a growing number of examples of this application of photography. ${ }^{34}$

\section{Raising awareness of diverse influences on health}

The WHO Health for All strategy has been built on the recognition that health is influenced by many factors. ${ }^{56}$ Indeed, almost all aspects of life touch on health. Growing concern about the global environment through Agenda-21 has also focused attention on the relations between society, environment and health. ${ }^{7}$ Raising awareness of these many and complex influences on health is therefore one of the most important functions of public health. In every society, there are many people whose work and responsibilities, while not carrying an explicit "health" label, can none the less influence the health of large numbers of people in ways that are at least as powerful as the activities of the formal health sector. Photographic images can help to achieve greater awareness and understanding of this, either through direct portrayal of physical and environmental threats and action taken to

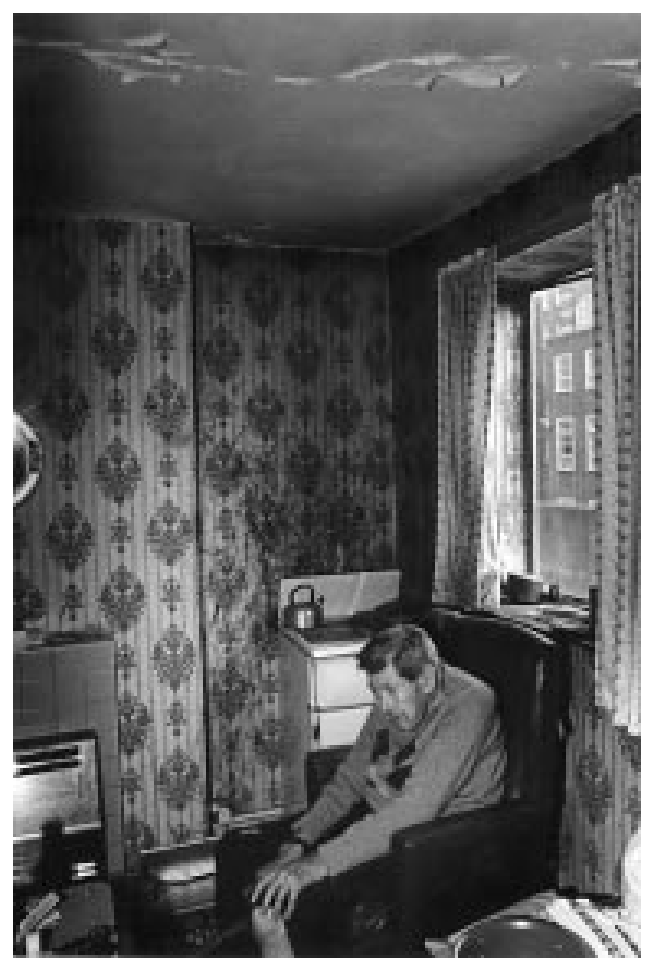

Figure 2 Too many older people still struggle with poverty, bad housing and loneliness. 
alleviate these, or through more subtle images of social relations and activities, and historical influences. ${ }^{8}$ (Figures 2-5).

Photographs can convey the extraordinary range and depth of factors that affect health, and stimulate all of us to consider ways in which we can work to improve health. A picture may be worth a thousand words, but those words will depend on the context in which the image is seen, and the experience of those viewing it. Although some images are powerful enough to stand on their own, ${ }^{9}$ more often photographs will be part of a story in which aspirations, settings, action and experience require to be documented, the context defined, and the implications for health debated. The process of seeking the images desired to express these complex inter-relationships is an important and formative one for those involved.

\section{Finding and creating the images}

Identifying the right subjects can, and often does, entail looking carefully and critically at common assumptions, anecdote, or stereotypes.

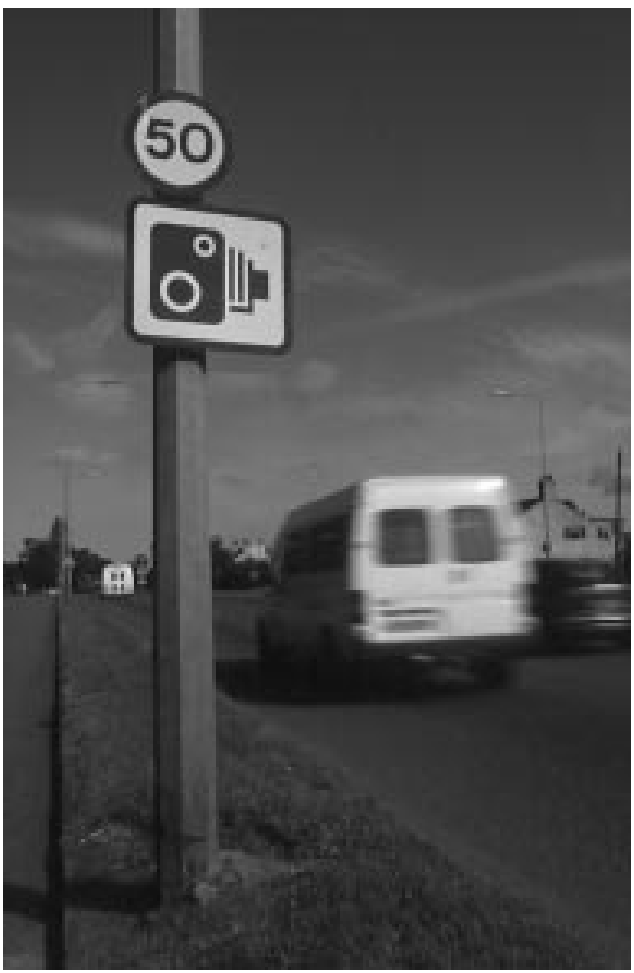

Figure 3 Traffic cameras are very effective at reducing vehicle speeds.

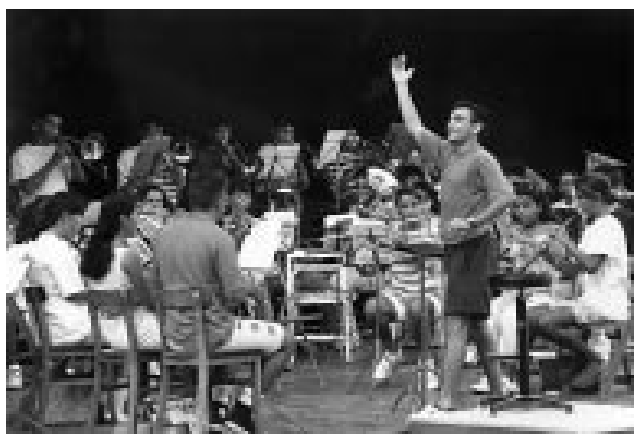

Figure 4 A picture of health? Youth orchestra, southern Spain.
From my experience of working with a number of community groups and organisations, I have found this to be one of the most challenging, yet valuable, parts of the process - and not just for the photographer. Some of these experiences, working with two very different projects on Merseyside, are now reported.

\section{The Norris Green Community Health Forum (NGCHF)}

The NGCHF is a group of local residents determined to re-build a centre for their community, which is situated on a peripheral 1930s estate in north east Liverpool. In recognition of their work, the Forum received a healthy communities award in 1996. This was to be presented at a large meeting in the United States, and they were asked to provide around 100 still pictures, which would be made into a short video illustrating their goals, achievements to date and future plans. ${ }^{10}$

As a first step, we talked through all of their activities and for each asked, "what is it about this that you think is important for the development and health of your community?" Much of this discussion ranged over changes to the physical and social environment that could build opportunity-especially for the young. This provided me with a lot of insight into the thinking behind their priorities, while for the Forum members it was a sometimes quite demanding exercise in nailing down images that could convey the most important themes and actions of their work. (Figure 6).

From a professional (public health) standpoint, the question of what evidence exists to support the belief that these ideas and activities would positively influence health was never far from the surface. In respect of this, there was quite an extensive background to the Forum's activities, including needs assessment work.

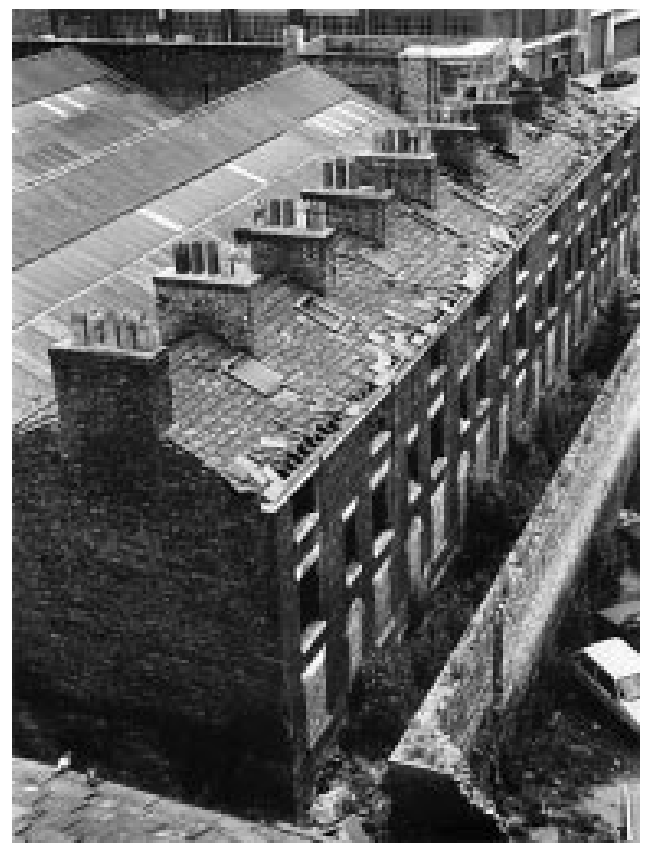

Figure 5 The sole remaining block of back to back houses in Liverpool. In the last century, many such blocks provided damp, desperately overcrowded accommodation for poor working families. 


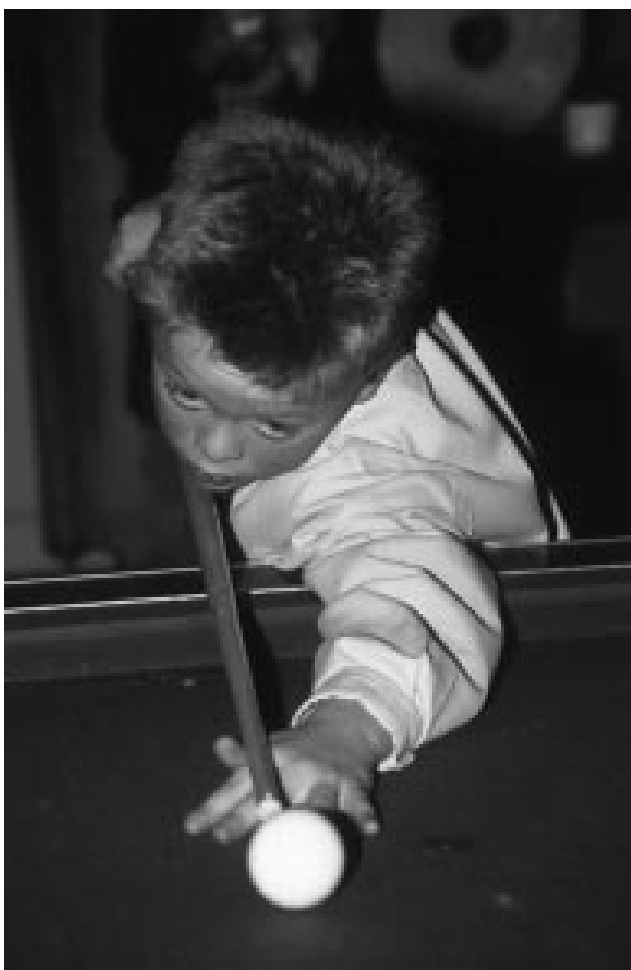

Figure 6 Concern about the future of children is central to the work of the Norris Green Community Health Forum

Although far from providing robust evidence of the links between inputs, processes and health outcomes, it did however provide information about priority health issues and the ways in which the community and statutory sectors were attempting to deal with these through joint working.

The NGCHF is closely involved in the Liverpool Healthy Cities project, more specifically as part of the Croxteth Health Action Area in North Liverpool. ${ }^{11}$ Over the previous few years, there had been a number of needs assessment studies, ${ }^{12}{ }^{13}$ and a history of building partnerships with various professional groups in the city. Broadly though, this "external" influence had facilitated rather than directed action by local residents. The issues they identified arose mainly from their extensive knowledge of the community, and what they felt so strongly was required to improve it and the health of those living there. A key element of the Forum's plan was to develop a multi-purpose centre on the site of a disused secondary school, incorporating health, housing, education and training services and facilities to promote individual confidence, skills, social support and health. Other initiatives included environmental improvements, a credit union, and activities for young people. Illustrated here is one of the most innovative projects supported and led by the Forum - the Supported Independent Living Project (SILP). This aims to ensure that local people with learning difficulties would be able to continue living in the community when those family members who had been caring for them were no longer able to do so. (Figure 7). Building local resources and opportunity through training and personal development, services and

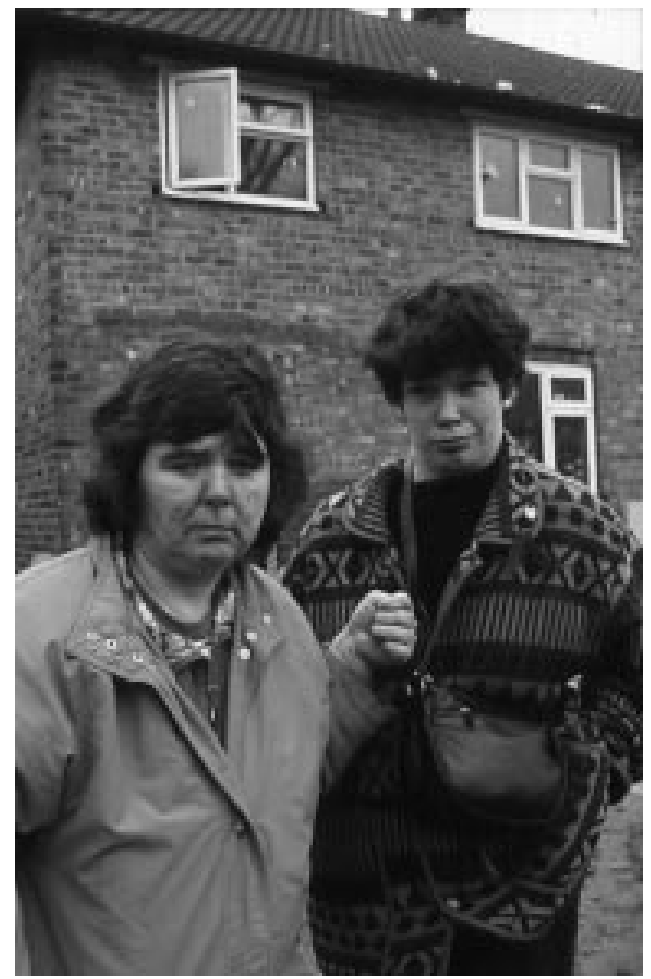

Figure 7 Two members of the Supported Independent Living Project (SILP), as their new homes near completion.

infrastructure are among the main guiding principles of the Forum.

\section{Wirral City Lands}

This assignment presented a different set of challenges. Wirral City Lands (WCL) was one of the City Challenge Projects, a five year programme of investment and partnership building designed to turn around the decline of inner city areas. While it seems certain that projects such as this have the potential to affect health in many ways, the question arises as to what health impacts might be, whether these can be demonstrated and quantified (for example in assessing cost-benefit) and how health gains can be maximised.

One problem of attempting to answer these questions through scientific evaluation is the complexity of the activities, both in terms of what projects such as WCL were directly implementing, but also through the effects of

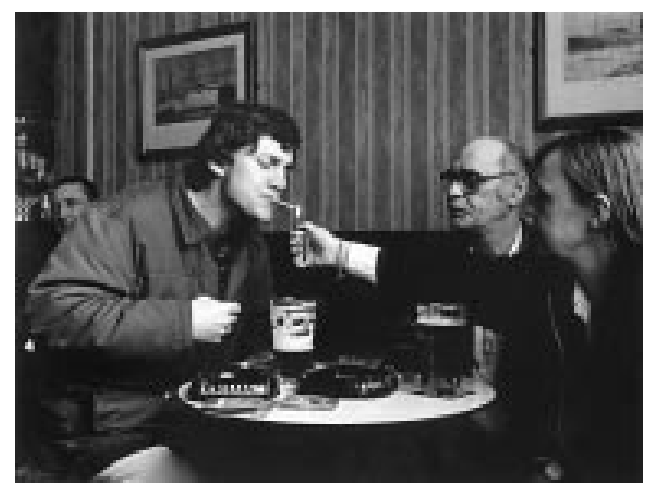

Figure 8 WCL was an area of high unemployment, lack of opportunity and poor health. 
other local, national and international inputs. Studying the effects of individual components may be interesting, but is artificial, because one of the main aims of WCL was to stimulate other local activity and investment, and to complement other areas of local, national and international policy. Although direct investment and action formed a part of the WCL project, the most important function was as a development catalyst. On the other hand, trying to study the "overall package" is extremely complex, and it becomes very difficult to isolate cause and effect. ${ }^{14}$

With these issues in mind, the aim of this project was to illustrate the range of activities and processes that made up the WCL initiative, and encourage people to think about and debate the likely consequences for healthmainly through a public exhibition. Through discussion of the project with the WCL coordinator, I identified two "dimensions" to the project that guided me in seeking representative images:

- The main areas of activity, such as transport infrastructure, housing, environmental improvement, development of sport and leisure facilities and activity, community education and training, etc.

- Levels of activity, from high level planning and investment partnership initiatives, through to much smaller scale activities located in specific areas of the community, or with specific groups. (Figure 9).

These themes were followed up through meetings with residents, people responsible for local services, and others to find locations that were representative and acceptable to those involved. One of the striking features of those discussions was how frequently people felt compelled to point out to me that their activities were not actually for health. What they meant was that they were not working in, or for, the formal health sector. Although somewhat anecdotal, this did seem to be something of a marker of how much further we still have to go before society feels comfortable with this central tenet of Health for All.

This work on WCL formed the major part of the images in the New Public Health gallery of an exhibition of historical and contemporary public health, Liverpool, A Healthy Place to Live?, displayed during 1997-98 in the $\mathrm{Mu}-$ seum of Liverpool Life. ${ }^{15}$ (Figures 10 and 11).

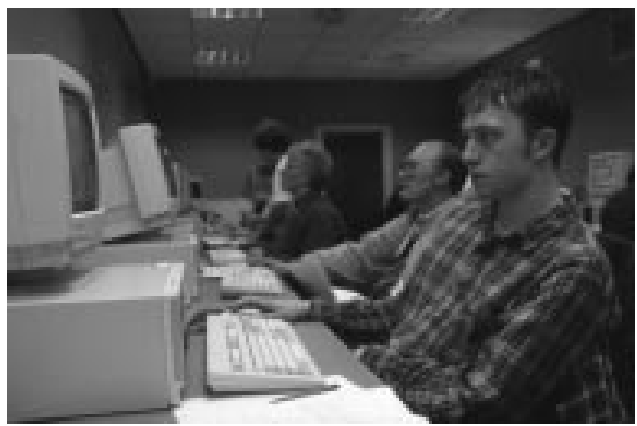

Figure 9 IT training in one of the new community colleges. Active links with local communities attempt to attract people who have become cut off from training and education opportunities.

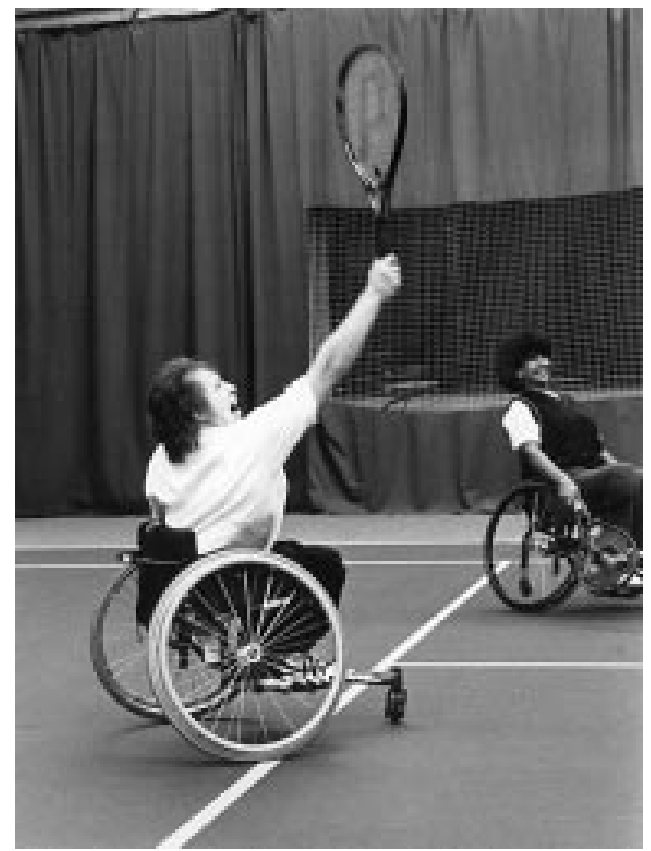

Figure 10 Sporting opportunities for disabled people required new facilities and organisation that had been lacking in the WCL area.

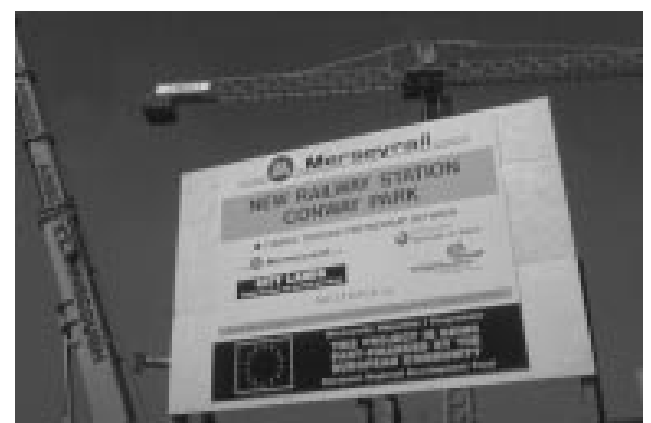

Figure 11 Construction of a new rail station, Birkenhead: recognition of the part that modern public transport facilities can play in urban development.

\section{Conclusions}

Photography may seem a relatively modest endeavour in the health field, compared with the apparent power of social and economic policy, the impact of major infrastructure development, or of modern medicine. Yet, who knows how much images such as Nick Ut's celebrated photograph of a naked, napalm burned girl running from the smoking remains of her village contributed to the change in public opinion that hastened the end of the Vietnam war? ${ }^{16}$ Indeed, Evans notes that "it is more than coincidence that the Vietnam war was at once the most unpopular in American history and the most photographed". ${ }^{17}$ Images such as that by Nick Ut are relatively rare (it won a world press photo award), yet much less dramatic or emotionally charged pictures can still mean a great deal to people at all levels whose lives are touched by the content. This is especially so if they have been involved in the process of identifying and creating those images.

I-as author-accept all responsibility for reproduction of the images submitted. This is on the basis that permission was given by the subjects to use the pictures in specific projects for which 
they were taken and for use so long as this is for the promotion of public health. Permission has not been given for any other lection being developed by the author, with the aim of illustratlection being developed by the author, with the aim of illustrating the breadth of influences on public health, and recording examples of action being taken - or required - to improve public health with an emphasis on multi-sectoral and participatory initiatives. For further information on images held and plans for the further development of this resource, please contact ngb@liv.ac.uk

1 Louth S. Riches beyond measure. British fournal of Photography 1998;145:16-19.

2 White M. Art as health. In: Bruce N, Springett J, Hotchkiss $\mathrm{J}$, et al, eds. Research and change in urban community health. Aldershot: Avebury, 1995:401-6.

3 Images of health and sickness: a collaborative project investigating people's health needs, using photography. Royal Infirmary of Edinburgh Gallery (21 October-16 November 1995). Edinburgh: Health Promotion Department of Lothian Health, 1995.

4 Jones J. Private troubles and public issues: a community development approach to health. Edinburgh: Community learning ment approach to health.

5 World Health Organisation. Global Strategy for Health for All by the Year 2000. Geneva: World Health Organisation, 1981.

6 WHO. Health 21 - health for all in the 21st century. An introduction. European health for all series no 5. introduction. European
7 Earth Summit '92. The United Nations conference on environment and development-Rio de faneiro 1992. London: Regency Press, 1992.

8 Morris M, Ashton J. The pool of life: a public health walk in Liverpool. Guildford: Biddles, 1997.

9 Evans H. Pictures on a page: photojournalism, graphics and picture editing. London: Heinemann, 1978:255.

10 Healthy Communities Awards 1995 (Presentation video). Carlsbad, CA: Ray Bloch Productions, 1995.

11 Bruce N, Winters L. Building community action: experience from the Croxteth Health Action Area, Liverpool. In: Bruce N, Springett J, Hotchkiss J, et al, eds. Research and change in urban community health. Aldershot: Avebury, 1995:111-28.

12 Habib J. Carer's needs of the CHAA. Liverpool: Liverpool School of Tropical Medicine, 1993.

13 Hotchkiss J. CHAA: Community needs survey and community response. Liverpool: Liverpool Public Health Observatory, report no $15,1993$.

14 Bruce N, Springett J, Hotchkiss J, et al, eds. Research and change in urban community health. Aldershot: Avebury, 1995:416-20.

15 Liverpool - a healthy place to live? (exhibition). Liverpool: Museum of Liverpool Life, 1997-98.

16 Evans H. Pictures on a page: photojournalism, graphics and picture editing. London: Heinemann, 1978:7-8.

17 Evans H. Pictures on a page: photojournalism, graphics and picture editing. London: Heinemann, 1978: introduction. 